\title{
Thermodynamic and Dynamic of Chromium Biosorption by Pectic and Lignocellulocic Biowastes
}

\author{
Sebastián Bellú ${ }^{1}$, Luis Sala ${ }^{1 *}$, Juan González ${ }^{1}$, Silvia García $^{1}$, María Frascaroli ${ }^{1}$, Patricia Blanes ${ }^{1}$, \\ Jousy García ${ }^{1}$, Juan Salas Peregrin ${ }^{2}$, Ana Atria ${ }^{3}$, Julio Ferrón ${ }^{4}$, Masafumi Harada ${ }^{5}$, Cong Cong ${ }^{6}$, \\ Yasuhiro Niwa ${ }^{6}$ \\ ${ }^{1}$ Instituto de Química Rosario, CONICET. Universidad Nacional de Rosario, Rosario, Argentine \\ ${ }^{2}$ Departamento de Química Inorgánica, Facultad de Ciencias, Universidad de Granada, Granada, Spain \\ ${ }^{3}$ Facultad de Ciencias Químicas y Farmacéuticas, Universidad de Chile, Santiago, Chile \\ ${ }^{4}$ Instituto de Desarrollo Tecnológico para la Industria Química, CONICET. Universidad Nacional del Litoral, \\ Santa Fe, Argentine \\ ${ }^{5}$ Faculty of Human Life and Environment, Nara Women's University, Nara, Japan \\ ${ }^{6}$ Photon Factory, High Energy Accelerator Research Organization (KEK), Tsukuba, Japan \\ E-mail: \{sala,gonzalez\}@iquir-conicet.gov.ar \\ Received July 12, 2010; revised August 10, 2010; accepted August 18, 2010
}

\begin{abstract}
Orange peel (OP) and rice husk (RH) were tested as low-cost biosorbents for $\mathrm{Cr}(\mathrm{III})$ removal from aqueous solutions. Dynamics of the biosorption process indicated that intraparticle mass transfer represents the rate-limiting step in the system that attained equilibrium at $120 \mathrm{~min}$. While the OP sorbent material was capable of taking up $39.11 \mathrm{mg} \mathrm{Cr}(\mathrm{III}) / \mathrm{g}$ at the optimum $\mathrm{pH} 4.4$, RH immobilized $3.20 \mathrm{mg} \mathrm{Cr}(\mathrm{III}) / \mathrm{g}$ at the optimum $\mathrm{pH}$ 3.0. The fitting of different sorption isotherms models resulted in the best fit with the Langmuir isotherm model. The mean free energy of the metal sorption process was in the range of $8-16 \mathrm{~kJ} / \mathrm{M}$. Abiotic $\mathrm{Cr}(\mathrm{VI})$ reduction was observed at various contact times and Cr-laden biomass was characterized by XPS, XAFS and EPR spectroscopy. These instrumental analyses confirmed that $\mathrm{Cr}(\mathrm{VI})$ removed from the solution was reduced and bound to the biomass as $\mathrm{Cr}(\mathrm{III})$. Results indicated that $\mathrm{OP}$ and $\mathrm{RH}$ materials are efficient biosorbents for eliminating Chromium from aqueous solutions.
\end{abstract}

Keywords: Chromium, Adsorption, Orange Peel, Rice Husk

\section{Introduction}

Chromium and its compounds are widely employed in industry [1] and $\mathrm{Cr}(\mathrm{III})$ is used as a tanning agent, resulting in severe groundwater contamination around tanneries [2,3]. Oxidation of polyuronic acids and pectin by hipervalent Chromium showed the presence of $\mathrm{Cr}(\mathrm{V})$, $\mathrm{Cr}(\mathrm{IV})$ and $\mathrm{Cr}(\mathrm{III})$-saccharide complexes, with $\mathrm{Cr}(\mathrm{III})$ pectin as an insoluble compound in the reaction media [4,5]. Following the treatment of $\mathrm{Cr}(\mathrm{VI})$ solution $\left([\mathrm{Cr}(\mathrm{VI})]_{0}=0.0176 \mathrm{M}\right)$ with $1.0 \mathrm{~g}$ of D-polygalacturonic acid, only $10 \%$ of the total $\mathrm{Cr}\left(\mathrm{Cr}_{\mathrm{T}}=\mathrm{Cr}(\mathrm{III})+\mathrm{Cr}(\mathrm{VI})\right)$ remained in solution [5].

Different metal removal methods (ion exchange, chemical reduction and precipitation, reverse osmosis, phytoremediation, bioremediation, etc.) have been tested for detoxification of Chromium-laden wastewaters in the recent years. However, these methods have high operating costs and problems in the disposal of the residual metal sludges. Biosorption techniques could use inexpensive sorbent materials as a feasible alternative for Chromium removal that features high efficiency, low operating costs with no adverse effects on the environment [6]. In recent years, several types of agricultural wastes such as sugarcane bagasse, grainless stalk of corn, etc. $[7,8]$ have been applied with the aim of removing Chromium from wastewaters.

In this work, we study the behavior of biomaterials with different proportions of polyuronic acids when contacted with Chromium-containing wastewater. The study focused on easily obtainable waste materials such as orange peels $(\mathrm{OP})$ and rice hulk $(\mathrm{RH})$ which contain high proportions of pectin and lignin, respectively. XPS, XAS and EPR techniques were used to determine the oxida- 
tion state of Chromium in the sorbent material, leading to establishing the mechanism of Chromium uptake/removal by OP and RH.

\section{Experimental Section}

\subsection{Materials}

The following analytical-grade reagents were used without purification: $\mathrm{K}_{2} \mathrm{Cr}_{2} \mathrm{O}_{7}, \mathrm{~K}_{2} \mathrm{CrO}_{4}, \mathrm{Cr}\left(\mathrm{NO}_{3}\right)_{3} \cdot 9 \mathrm{H}_{2} \mathrm{O}, \mathrm{Cr}_{2} \mathrm{O}_{3}$, $\mathrm{Na}_{2} \mathrm{CO}_{3}, \mathrm{~K}_{2} \mathrm{~S}_{2} \mathrm{O}_{8}, \mathrm{AgNO}_{3}, 1,5$-diphenylcarbazide (DPC), and diphenylpicrylhydrazyl (dpph) (Sigma Grade). Na$\left[\mathrm{CrO}(\mathrm{V})(\mathrm{ehba})_{2}\right] \cdot \mathrm{H}_{2} \mathrm{O}$ was synthesized [9].

OP was obtained from oranges harvested near the city of Rosario (Argentina) and RH came from a rice mill located in San Javier (Argentina). Both, OP and RH were washed with water, dried at $40^{\circ} \mathrm{C}$ for $12 \mathrm{~h}$, powdered and sieved to retain the fraction of particles in the size range of $0.3-1.2 \mathrm{~mm}$ (OP) or $0.3-0.5 \mathrm{~mm}(\mathrm{RH})$, and were stored at room temperature in sealed polyethylene bags.

The reference solid compounds: oxidation state of $\mathrm{Cr}(\mathrm{VI})$ as $\mathrm{K}_{2} \mathrm{CrO}_{4}, \mathrm{Cr}(\mathrm{V})$ as $\mathrm{Na}\left[\mathrm{CrO}(\mathrm{V})(\text { ehba) })_{2}\right] \cdot \mathrm{H}_{2} \mathrm{O}$, and $\mathrm{Cr}(\mathrm{III})$ as $\mathrm{Cr}\left(\mathrm{NO}_{3}\right)_{3} \cdot 9 \mathrm{H}_{2} \mathrm{O}$ and $\mathrm{Cr}_{2} \mathrm{O}_{3}$.

\subsection{Chromium Analysis}

The $[\mathrm{Cr}(\mathrm{VI})]$ was determined at $540 \mathrm{~nm}$ by using a double-beam UV-vis JASCO V-550 spectrophotometer after complexation with DPC $[10] .[\mathrm{Cr}]_{\mathrm{T}}=[\mathrm{Cr}(\mathrm{VI})]+[\mathrm{Cr}(\mathrm{III})]$ was determined by oxidizing $\mathrm{Cr}$ (III) to $\mathrm{Cr}(\mathrm{VI})$ using $\mathrm{K}_{2} \mathrm{~S}_{2} \mathrm{O}_{8}$ and $\mathrm{AgNO}_{3}$ saturated solution as catalyst [11], prior to the DPC reaction. [Cr(III)] was calculated as the difference between $[\mathrm{Cr}]_{\mathrm{T}}$ and $[\mathrm{Cr}(\mathrm{VI})]$. The amount of $\mathrm{Cr}$ sorbed by the OP and RH biomass exposed to $\mathrm{Cr}$ (III) and $\mathrm{Cr}$ (VI) solutions was calculated from the difference between the initial chromium concentration of the control solutions and the final total $\mathrm{Cr}$ concentration in the respective supernatant solutions.

\subsection{Spectroscopic Analysis}

Cr-laden solid biomaterial samples were examined by EPR, XPS and XAS spectroscopy. The EPR spectra were derived on a Bruker ESP 300 E spectrometer at room temperature. XPS analyses were done with a SPECS system equipped with a hemispherical energy analyzer, a nine channeltron detector System and a double anode X-ray source. XAS experiments at the Cr K-edge (5989 $\mathrm{eV}$ ) were carried out at beamline BL-9A with a ring energy of $2.5 \mathrm{GeV}$ and a ring current of $450 \mathrm{~mA}$. A doublecrystal $\mathrm{Si}(111)$ monochromator was used, and the beam was focused using a pair of bent conical mirrors coated with $\mathrm{Rh}$ [12]. XAFS measurements were performed in a transmission mode for Cr-laden OP samples (Cr loading
$4.9 \mathrm{wt} \%$ ) and in fluorescence a mode for Cr-laden $\mathrm{RH}$ samples (Cr loading $0.71 \mathrm{wt} \%$ ), respectively. The spectra of Cr-laden OP samples were recorded in transmission mode, with $\mathrm{N}_{2}(30)-\mathrm{He}(70)$ gas for the $\mathrm{I}_{0}$ chamber and $\mathrm{N}_{2}$ gas for the I chamber to monitor the incident and transmitted X-rays, respectively. On the other hand, the spectra of Cr-laden RH samples were collected in a fluorescence mode, using an argon-filled Lytle detector with a vanadium filter $(\mu \mathrm{t}=6)$ for monitoring the fluorescent $\mathrm{X}$-ray $\left(\mathrm{I}_{\mathrm{f}}\right)$. The XANES spectra were measured with 0.35 eV steps and $1 \mathrm{~s}$ collecting time between 5980 and 6060 $\mathrm{eV}$, while the EXAFS spectra were measured with 2.5 $\mathrm{eV}$ steps and $4 \mathrm{~s}$ (in transmission mode) or $8 \mathrm{~s}$ (in fluorescence mode) collecting time between 5500 and 7080 eV. XAFS data were analyzed with commercially available software (REX2000 program, Rigaku Co.). EXAFS analysis was performed as described in detail elsewhere [13]. The reference samples were used to compare their spectral shapes and to identify major $\mathrm{Cr}$ species on the biomaterial surface [14].

\subsection{Batch Studies}

\subsubsection{Effect of pH, Contact Time and Biomass Dosage on Cr(III) Adsorption}

Batch equilibrium sorption studies were carried out at $20.0 \pm 1.0^{\circ} \mathrm{C}$. Biomaterials were suspended in Erlenmeyer flasks with an appropriate volume of work under constant stirring. $[\mathrm{Cr}(\mathrm{III})]_{0}$ was $0.77 \mathrm{mM}$ and $0.44 \mathrm{mM}$ for $\mathrm{OP}$ and $\mathrm{RH}$ respectively. $\mathrm{pH}$ ranged from 0.2 to 5.2 ; $\mathrm{pH}$ was constantly controlled using a $\mathrm{pH}$ controller. A total amount of $5.0 \mathrm{~g}$ and $1.25 \mathrm{~g}$ of RH and OP, respectively, was used in these experiments. Time-based sorption uptake studies (process dynamics, including mass transfer and reaction) were carried out at $20.0 \pm 1^{\circ} \mathrm{C}$, using a series of $150 \mathrm{~mL}$ Erlenmeyer flasks. For Cr(III) sorption by OP, $1.50 \mathrm{~g}$ was suspended in $75.0 \mathrm{~mL}$ of $\mathrm{Cr}$ (III) solution at $\mathrm{pH}$ 4.0. $\mathrm{Cr}$ (III) sorption by $\mathrm{RH}$ was performed using $5.0 \mathrm{~g}$ of sorbent suspended in $50.0 \mathrm{~mL}$ of $\mathrm{Cr}$ (III) solution at $\mathrm{pH}$ 3.0. Mixtures were magnetically stirred and samples withdrawn at different time intervals followed by centrifugal solids separation. Clear supernatants were analyzed for their $\mathrm{Cr}$ content. Separate controls were maintained for each period of time. All experiments were performed in triplicate for statistical purposes.

\subsubsection{Adsorption Isotherms}

Equilibrium sorption experiments were performed under optimum conditions derived using factorial design. The sorbent material (OP or $\mathrm{RH}$ ) was exposed to varying concentrations of $\mathrm{Cr}(\mathrm{III})$ in Erlenmeyer flasks containing $75.0 \mathrm{~mL}$ or $50.0 \mathrm{~mL}$ of solution. The $\mathrm{pH}$ was adjusted to 4.4 or 3.0 for OP or RH, respectively. The biosorbent 
dosage was $1.45 \mathrm{~g}$ and $5.65 \mathrm{~g}$ for OP and $\mathrm{RH}$, respectively. The $\mathrm{Cr}(\mathrm{III})$ adsorption experiments were performed at $20.0 \pm 0.1^{\circ} \mathrm{C}$. Mixtures were stirred for 120 min to reach equilibrium and then centrifuged. The supernatants were analyzed for their $\mathrm{Cr}$ content. All experiments were performed in triplicate for statistical purposes.

\section{Results and Discussion}

\subsection{Cr-laden Biomaterials Spectroscopic Characterization}

Characterization of the Chromium oxidation state on the surface of the biomaterial would establish if $\mathrm{Cr}(\mathrm{VI})$ adsorption-reduction mechanism contributes to its removal from the aqueous solution. Grainless stalk of corn (GLSC), an agricultural waste, was tested as a reference biomass for sorption and reduction of $\mathrm{Cr}(\mathrm{VI})$ [8]. The reduction took place mainly in the presence of solid biomaterial. High-resolution XPS of Cr-laden GLSC showed the presence of $\mathrm{Cr}(\mathrm{V})$ and $\mathrm{Cr}(\mathrm{III})$ at short contact time (Figure 1(a)) and only $\mathrm{Cr}(\mathrm{III})$ at prolonged contact time (Figure 1(b)).

The present experimental results support the conclusion of Park et al. [16] that the mechanism of $\mathrm{Cr}(\mathrm{VI})$ removal by GLSC is $\mathrm{Cr}(\mathrm{VI})$ sorption-coupled reduction to $\mathrm{Cr}$ (III) and partial complexation of $\mathrm{Cr}$ (III).

Figure 2 shows XPS spectra of Cr-laden OP. As can be seen in the high-resolution XPS spectrum of longexposure Cr-laden OP, it was $\mathrm{Cr}$ (III) that became bound to the sorbent. While at short contact time, the amount of $\mathrm{Cr}$ sorbed by OP was below the XPS detection limit giving thus no discernible spectrum, at long contact times the amount of $\mathrm{Cr}$ sorbed was sufficient to produce an XPS spectrum with a $\mathrm{Cr}$ signal. Similarly, no chromium signal could be detected in the XPS spectrum of Cr-laden RH where $\mathrm{Cr}$ was still below the apparatus detection limit. The detection of intermediate states of Chromium for short contact times could be improved employing a more sensitive spectroscopic technique such as EPR. The EPR spectra are shown in Figures 3 and 4.

EPR spectra of Cr-laden OP and Cr-laden RH for different contact-time samples exhibit a sharp signal at $\mathrm{g}_{\text {iso }}$ $=1.9788$ and $\mathrm{g}_{\text {iso }}=1.9785$, respectively, characteristic of $\mathrm{Cr}(\mathrm{V})$, superimposed on a broad signal $(\sim 600 \mathrm{G})$ at $\mathrm{g}_{\text {iso }} \sim$ 2.00 , typical of $\mathrm{Cr}$ (III). The intensity of this broad signal increased for longer-contact time samples while the sharp $\mathrm{Cr}(\mathrm{V})$ signal diminished and finally disappeared, indicating thus that $\mathrm{Cr}(\mathrm{V})$ in these biosorbents was further reduced to $\mathrm{Cr}(\mathrm{III})$. The $\mathrm{g}_{\text {iso }}$ value of the $\mathrm{Cr}(\mathrm{V}) \mathrm{EPR}$ signal provides useful information on the nature and number of donor groups bound to $\mathrm{Cr}(\mathrm{V})$. The $\mathrm{g}_{\text {iso }}$ values 1.9788 and 1.9785 correspond to oxo- $\mathrm{Cr}(\mathrm{V})$ bound to

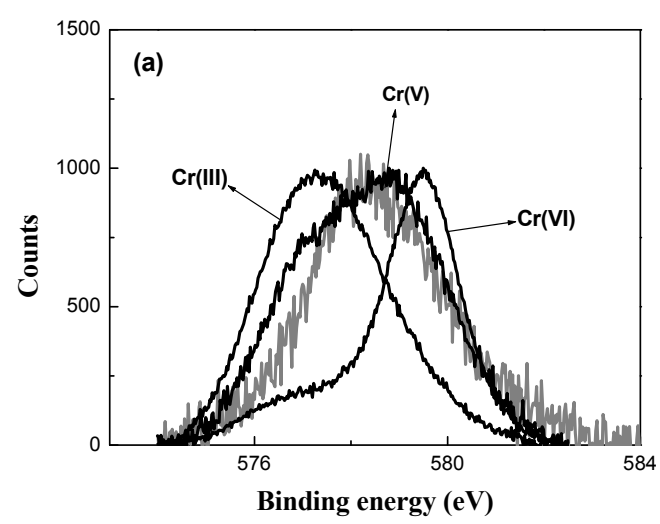

(a)

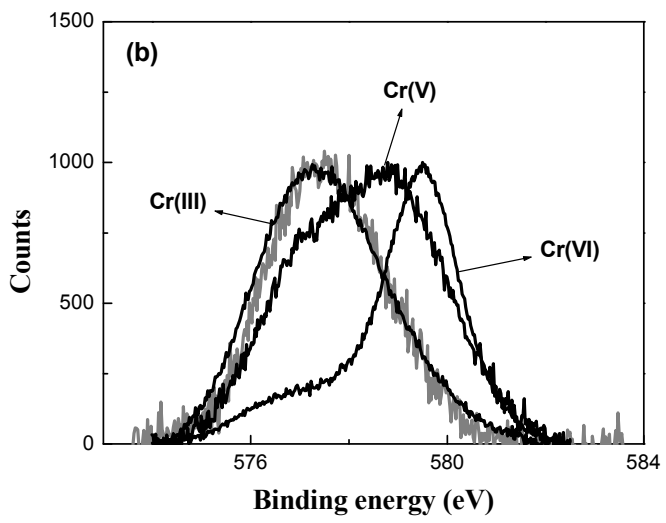

(b)

Figure 1. High-resolution XPS of Cr(VI)-laden GLSC. $\operatorname{Mass}_{\mathrm{GLSC}}=0.3 \mathrm{~g} ; \mathrm{V}=\mathbf{2 5 . 0} \mathrm{mL} ; \mathrm{pH}=0.9 ;[\mathrm{Cr}(\mathrm{VI})]=624$ $\mathrm{mg} / \mathrm{L}$; contact time: (a) $12 \mathrm{~h}$; (b) 1 week.

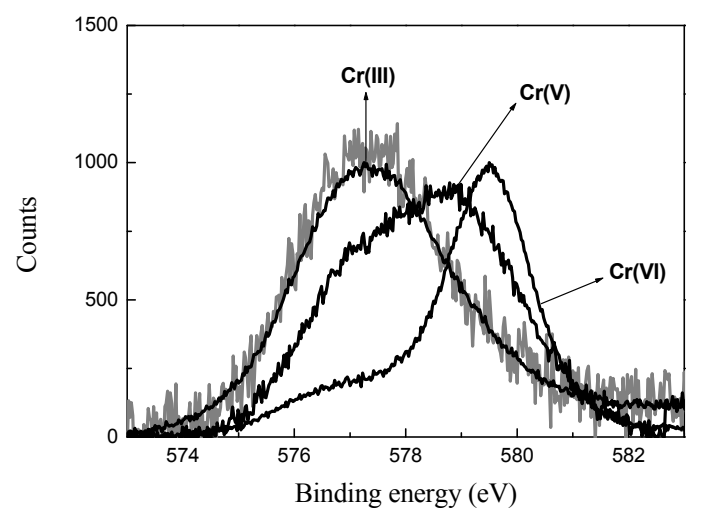

Figure 2. High-resolution XPS of Cr(VI)-laden OP. Mass ${ }_{O P}$ $=0.3 \mathrm{~g} ; \mathrm{V}=25 \mathrm{~mL} ; \mathrm{pH}=2 ;[\mathrm{Cr}(\mathrm{VI})]=624 \mathrm{mg} / \mathrm{L}$; contact time: 1 week.

carboxylate and alcohol groups [17]. The detection of $\mathrm{Cr}(\mathrm{V})$ bound by OP and $\mathrm{RH}$ biomaterials reinforces the sorption-reduction model hypothesis for the removal of $\mathrm{Cr}(\mathrm{VI})$ by these biosorbents. In both sorbents exposed to $\mathrm{Cr}(\mathrm{VI}), \mathrm{Cr}(\mathrm{III})$ was the final species as can be seen in the EPR and XPS spectra.

XPS spectroscopy was also employed for detection of 


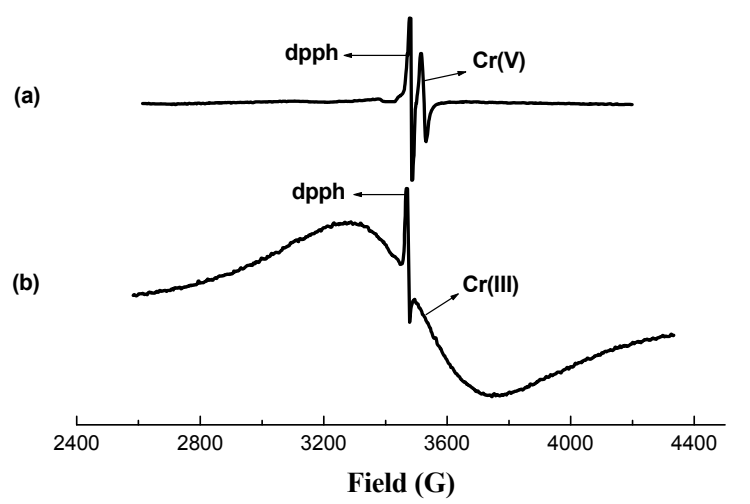

Figure 3. EPR spectra of $\mathrm{Cr}$-laden $\mathrm{OP}$ at various contact time. Mass $_{\mathrm{OP}}=0.2 \mathrm{~g} ; \mathrm{V}=75 \mathrm{~mL} ; \mathrm{pH}=\mathbf{2 . 0} ;[\mathrm{Cr}(\mathrm{VI})]_{0}=624$ $\mathrm{mg} / \mathrm{L}$; contact time: (a) $12 \mathrm{hs;} \mathrm{(b)} 1$ week.

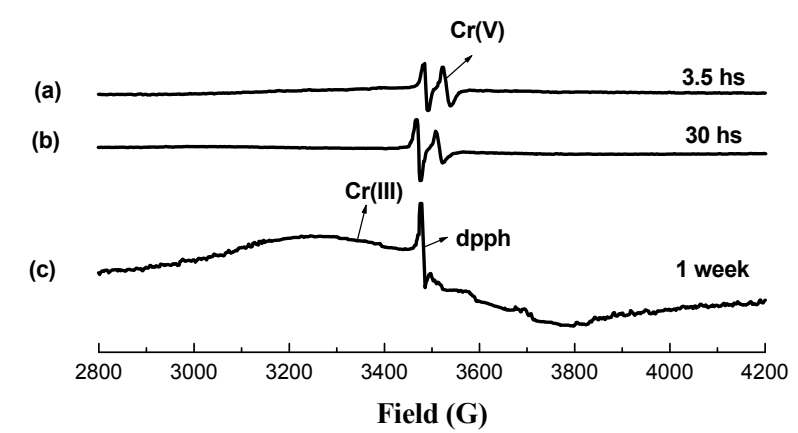

Figure 4. EPR spectra of Cr-laden RH at various contact time. Mass $_{\mathrm{RH}}=0.2 \mathrm{~g} ; \mathrm{V}=50 \mathrm{~mL} ; \mathrm{pH}=\mathbf{2 . 0} ;[\mathrm{Cr}(\mathrm{VI})]_{0}=624$ $\mathrm{mg} / \mathrm{L}$; contact time: (a) $3.5 \mathrm{hs}$; (b) $30 \mathrm{hs}$; (c) 1 week.

$\mathrm{Cr}$ (III) in metal-laden biomaterials and compared with a model complex $\mathrm{Cr}(\mathrm{III})$-pectinate and $\mathrm{Cr}_{2} \mathrm{O}_{3}$.

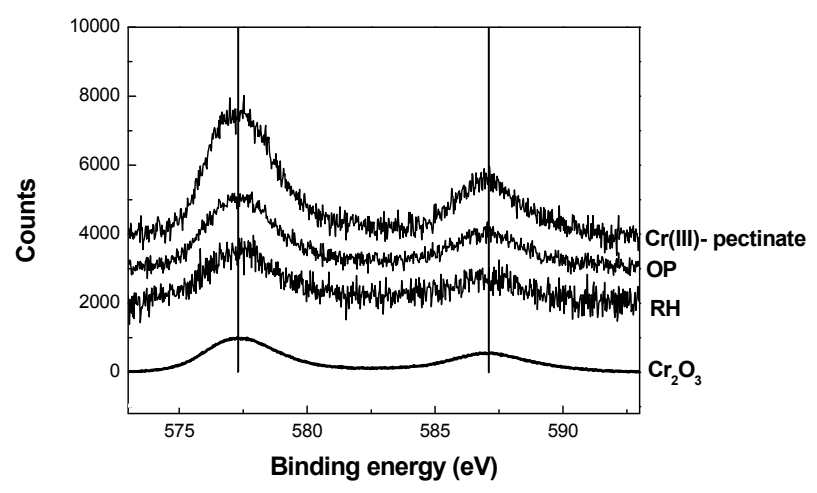

Figure 5. High-resolution XPS of Cr(III)-laden biomaterials. Mass $_{\text {biomaterial }}=0.3 \mathrm{~g} ; \mathrm{V}=25 \mathrm{~mL} ; \mathrm{pH}=4 ;[\mathrm{Cr}(\mathrm{III})]=624$ $\mathrm{mg} / \mathrm{L}$; contact time: 1 week.

High-resolution XPS spectra collected from the Cr2p core region indicated that there were significant contributions of the $\mathrm{Cr}$ bound to the biomaterials. Figure 5 shows bands of $\mathrm{Cr}_{2} \mathrm{O}_{3}(576.8$ and $586.7 \mathrm{eV})$. The spectra of all the $\mathrm{Cr}(\mathrm{III})$-laden biomaterials (OP, RH) could well be matched with that of the $\mathrm{Cr}_{2} \mathrm{O}_{3}$, similarly as with $\mathrm{Cr}$ (III)-pectinate. This fact indicates that $\mathrm{Cr}$ (III) is bound to oxygen atoms in the solid structures of the biosorbent. The XANES data were used to verify the oxidation state of the $\mathrm{Cr}(\mathrm{VI})$ - or $\mathrm{Cr}(\mathrm{III})$-laden biomass. Figure 6 shows the normalized Cr K-edge XANES spectra of reference compounds. The XANES data for Cr(III) standards show a small peak at $5990.5 \mathrm{eV}$, while those for $\mathrm{Cr}(\mathrm{V})$ and $\mathrm{Cr}(\mathrm{VI})$ show a pre-edge peak at 5993.0 and $5993.3 \mathrm{eV}$, respectively. The edge energy and the intensity of preedge absorbance decrease in the following order:
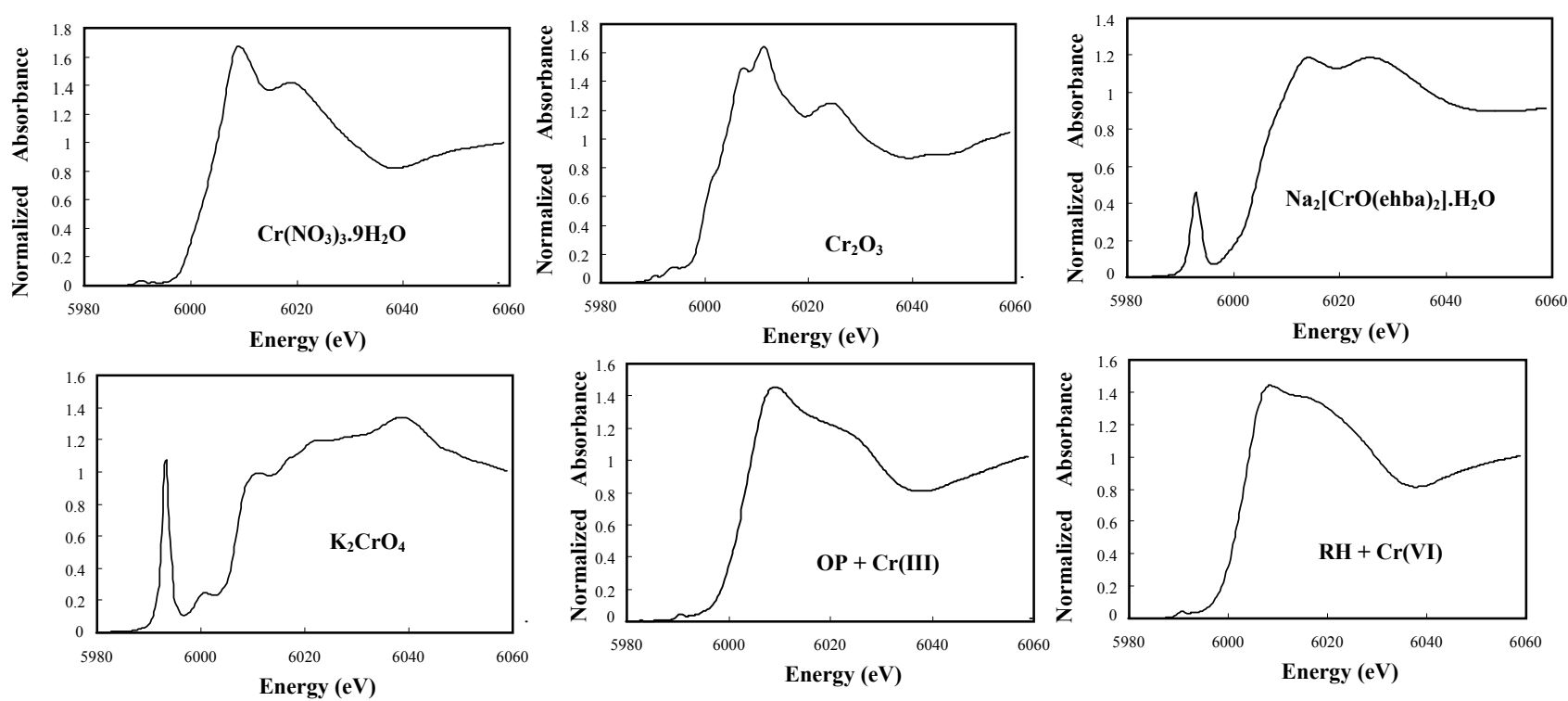

Figure 6. Cr K-edge XANES spectra of solid samples. 
$\mathrm{Cr}(\mathrm{VI})>\mathrm{Cr}(\mathrm{V})>\mathrm{Cr}(\mathrm{III})$. The octahedral symmetry in XANES spectra of $\mathrm{Cr}(\mathrm{III})$ compounds is characterized by small resonances in the pre-edge region as signed to transitions of $1 \mathrm{~s}$ electrons into antibonding orbitals with octahedral symmetry [18] whereas $\operatorname{Cr}(0)$ (body centered cubic) shows a broad pre-edge conduction band feature. The XANES data for $\mathrm{K}_{2} \mathrm{CrO}_{4}$ show the well-defined preedge peak from 5990 to $5997 \mathrm{eV}$ [19], and for Na$\left[\mathrm{Cr}(\mathrm{V}) \mathrm{O}(\mathrm{ehba})_{2}\right] \cdot \mathrm{H}_{2} \mathrm{O}$, the pre-edge peak position is consistent with that reported in the literature [20].

On the other hand, both $\mathrm{Cr}(\mathrm{III})-$ laden OP and $\mathrm{Cr}(\mathrm{VI})-$ laden RH samples do not show a pre-edge peak between 5990 and $5997 \mathrm{eV}$, and they have a small peak at 5990.5 $\mathrm{eV}$, indicating the presence of $\mathrm{Cr}(\mathrm{III})$ binding in both biomaterials. It is also evident that $\mathrm{Cr}(\mathrm{III})$ is bound in the $\mathrm{OP}$ and $\mathrm{Cr}(\mathrm{VI})$ sorbed by the $\mathrm{RH}$ is completely reduced to $\mathrm{Cr}(\mathrm{III})$. This is quite consistent with the XPS and EPR results. EXAFS spectroscopy was employed to determine the local atomic structure of $\mathrm{Cr}$ in $\mathrm{Cr}$ (III)-laden $\mathrm{OP}$ and $\mathrm{Cr}(\mathrm{VI})$-laden RH biomaterials. The experimental Fourier transform results are shown in Figure 7 and the curvefitted values are given in Table $\mathbf{1}$.

For $\mathrm{Cr}\left(\mathrm{NO}_{3}\right)_{3} \cdot 9 \mathrm{H}_{2} \mathrm{O}$, the $k^{3}$-weighted FT function gave a main peak centered at $1.60 \AA$ which arises from firstshell oxygen back-scattering and another smaller peak centered at $\sim 3.15 \AA$ (phase-uncorrected). Three main peaks at $1.60,2.52$, and $3.31 \AA$ (phase-uncorrected) could also be observed for the $\mathrm{Cr}_{2} \mathrm{O}_{3}$ compound, assigned to the first, second, and third shell contributions of a $\mathrm{Cr}(\mathrm{III})$ in an octahedral symmetry, respectively. For $\mathrm{Na}\left[\mathrm{Cr}(\mathrm{V}) \mathrm{O}(\text { ehba })_{2}\right] \cdot \mathrm{H}_{2} \mathrm{O}$, a main peak is observed at 1.47
$\AA$. The structure of the first coordination shell in the $\mathrm{Cr}(\mathrm{V})$ seems to be similar to that in the $\mathrm{Cr}(\mathrm{III})$. The Fourier transformed EXAFS spectra for the Cr(III)-laden OP and $\mathrm{Cr}(\mathrm{VI})$-laden $\mathrm{RH}$ biomaterials were very similar to those for $\mathrm{Cr}$ (III) reference compound. This result means that the coordination environment of the chromium on the OP and RH biomaterials was also similar to that of $\mathrm{Cr}$ (III) compound, where $\mathrm{Cr}$ (III) is in an octahedral geometrical arrangement. The $\mathrm{Cr}-\mathrm{O}$ bond distances were approximately the same lengths, which corresponds to the Cr-O bond lengths cited in the literature [18,21,22]. $\mathrm{Cr}(\mathrm{III})$-laden OP sample showed the presence of the second and third peaks of $\mathrm{Cr}_{2} \mathrm{O}_{3}$ allowing thus a guess as to the formation of Chromium polynucleate species [23]. For the curve-fitting to determine the structural parameters, phase and amplitude functions for the absorbing and back-scatterer $(\mathrm{Cr}, \mathrm{O})$ pair were extracted from the filtering of the first peak of the EXAFS Fourier transform

Table 1. Cr K-edge EXAFS fitting results for reference samples and Cr-laden biomaterials.

\begin{tabular}{ccccccc}
\hline Sample & Bond & $\mathrm{CN}$ & $r(\AA)$ & $\Delta E(\mathrm{eV})$ & $\sigma(\AA)$ & $R(\%)$ \\
\hline $\mathrm{Cr}_{2} \mathrm{O}_{3}$ & $\mathrm{Cr}-\mathrm{O}$ & 5.7 & 1.97 & 0.238 & 0.063 & 0.226 \\
$\mathrm{Na}\left[\mathrm{CrO}(\mathrm{ehba})_{2}\right]$ & $\mathrm{Cr}-\mathrm{O}$ & 2.4 & 1.91 & -0.961 & 0.075 & 7.847 \\
$\mathrm{~K}_{2} \mathrm{CrO}_{4}$ & $\mathrm{Cr}-\mathrm{O}$ & 3.8 & 1.66 & 1.089 & 0.066 & 1.931 \\
& & & & & & \\
$\mathrm{OP}+\mathrm{Cr}(\mathrm{III})$ & $\mathrm{Cr}-\mathrm{O}$ & 6.1 & 1.97 & -0.903 & 0.072 & 0.261 \\
$\mathrm{RH}+\mathrm{Cr}(\mathrm{VI})$ & $\mathrm{Cr}-\mathrm{O}$ & 5.2 & 1.96 & -1.605 & 0.049 & 0.456 \\
\hline
\end{tabular}
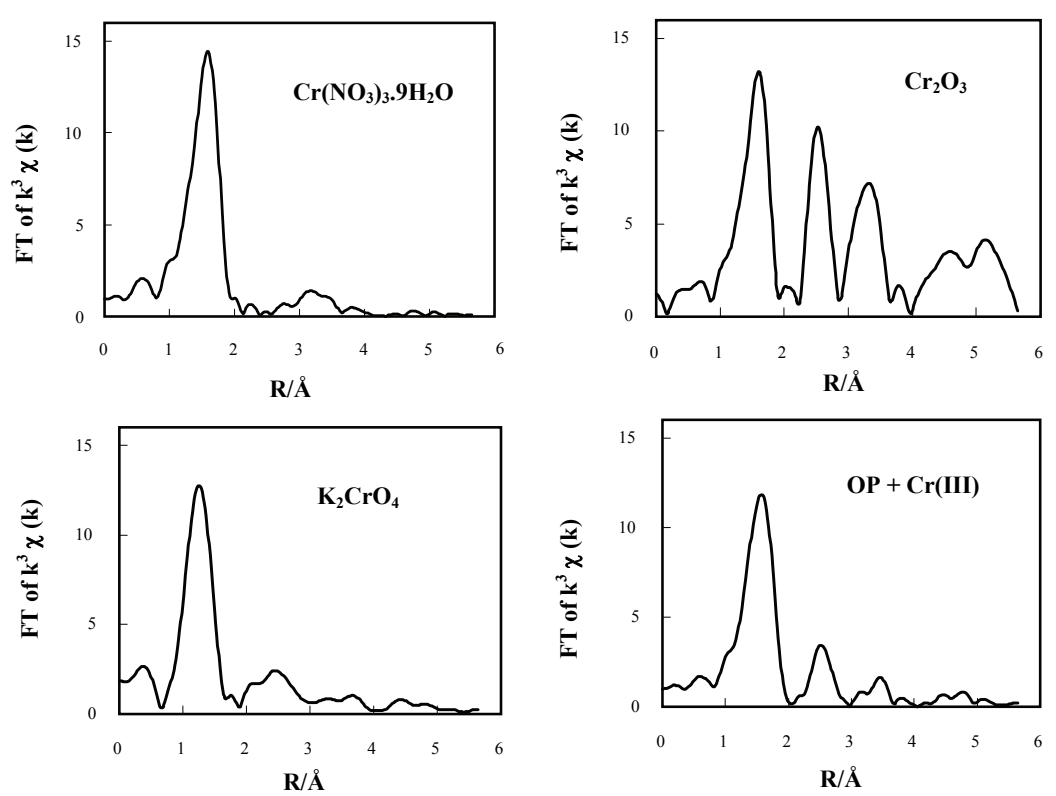

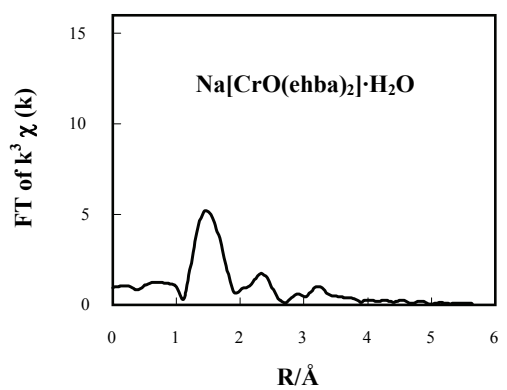

Figure 7. Fourier-transformed EXAFS spectra of solid samples. 
of $\mathrm{Cr}\left(\mathrm{NO}_{3}\right)_{3} .9 \mathrm{H}_{2} \mathrm{O}$, where the chromium absorbing atom is surrounded by 6 oxygen atoms at the bond distance of $1.96 \AA[21]$.

\subsection{Effect of $\mathrm{pH}$}

The effect of $\mathrm{pH}$, on the removal of $\mathrm{Cr}$ (III) by OP and $\mathrm{RH}$ is shown in Figure 8. The uptake of $\mathrm{Cr}$ (III) ion increased with increasing $\mathrm{pH}$ and $\mathrm{OP}$ biomaterial was more efficient in the removal. At $\mathrm{pH} \leq 1.0$ there was a small adsorption, less than $7-25 \%$ for $\mathrm{RH}$ or OP respectively and $\mathrm{Cr}$ (III) removal yield increased up to $86-98 \%$ at $\mathrm{pH}$ 3.0-4.0 for OP. RH showed a capacity something smaller than OP for $\mathrm{Cr}$ (III) adsorption. In spite of employing four times biomass, only 78.0-85.0\% was achieved at $\mathrm{pH}$ 3.0-4.0. At lower $\mathrm{pH}$ values, the higher $\left[\mathrm{H}^{+}\right]$effectively leads to fewer ligands being available for metal ions binding [24]. According to the $\mathrm{pH}$ dependence of this biosorption process, deprotonation of the carboxylic groups of uronic pectin moieties [4,5] might be involved. Increasing $\mathrm{pH}$, surfaces becomes deprotonated, resulting in more ligand groups available for $\mathrm{Cr}$ (III) cations binding and electrostatic attraction available from carboxylate groups is likely enhanced. Thus, at high $\mathrm{pH}$ values where the $\left[\mathrm{H}^{+}\right]$is very low, carboxylic groups from OP and $\mathrm{RH}$ work as ion exchanger, where protons are released in the solution while metal ions are sorbed.

\subsection{Sorption Process Dynamics}

Reaction kinetics of the sorption process that is based on ion exchange is inherently very fast and studying it is experimentally difficult and inaccurate. With biosorbent particles involved that are "transparent" to ionic species, it is predominantly the intraparticle mass transfer that is observed externally and that represents the rate-limiting

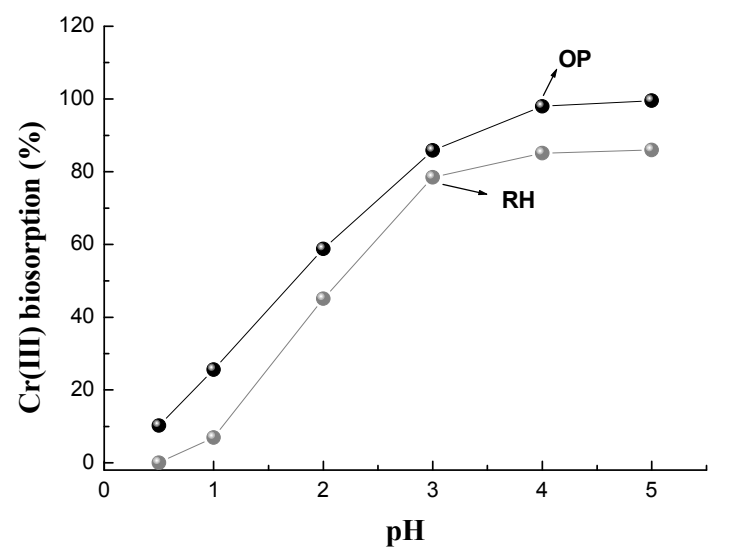

Figure 8. Effect of $\mathrm{pH}$ on the removal of $\mathrm{Cr}$ (III) by OP and RH. $\mathrm{T}=20^{\circ} \mathrm{C} ; \mathrm{V}=75.0 \mathrm{~mL} ;[\mathrm{Cr}(\mathrm{III})]_{0}=0.77 \mathrm{mM}(\mathrm{OP})$ and $0.44 \mathrm{mM}(\mathrm{RH})$; mass $=5.0 \mathrm{~g}(\mathrm{OP})$ and $1.25 \mathrm{~g}(\mathrm{RH})$. step. With easily accessible surface layers of the particles saturating first and fast, biosorption of $\mathrm{Cr}$ (III) onto $\mathrm{OP}$ and $\mathrm{RH}$ features two apparent steps, a fast initial sorption followed by a slower phase that reflects the penetration of sorbate into the particles. Correspondingly, the biosorption uptake increased sharply in the first $30 \mathrm{~min}$, with more than $80 \%$ of $\mathrm{Cr}$ (III) taken up, and then continued increasing only at much slower rate. The sorption system equilibrium was reached in less than $120 \mathrm{~min}$. A distinct two-step behavior has often been reported for metal ion biosorption. While Liu and Huang [25] attributed the two-step sorption characteristic to the heterogeneity of the surface binding sites on sorbents, Qin et al. [26] asserted that the fast initial sorption was the result of the fast transfer of metal ions to the surface of biomaterial, followed by a relatively slow uptake caused by the slow diffusion of metal ions into the intra-particle spaces of sorbents.

We tested of three kinetic models approach in order to stablish the mechanism of $\mathrm{Cr}$ (III) adsorption onto OP/RH. Pseudo-first-order kinetic model (Lagergren [27]) is:

$$
\frac{\mathrm{dq}}{\mathrm{dt}}=\mathrm{k}_{1}\left(\mathrm{q}_{\mathrm{e}}-\mathrm{q}_{\mathrm{t}}\right)
$$

Pseudo-second-order kinetic expression (Ho [28]) is:

$$
\frac{\mathrm{dq}_{\mathrm{t}}}{\mathrm{dt}}=\mathrm{k}_{2}\left(\mathrm{q}_{\mathrm{e}}-\mathrm{q}_{\mathrm{t}}\right)^{2}
$$

$\mathrm{k}_{1}(1 / \mathrm{min})$ and $\mathrm{k}_{2}(\mathrm{~g} / \mathrm{mg} \mathrm{min})$ are the equilibrium rate constant of pseudo-first and pseudo-second order sorption respectively, and $\mathrm{q}_{\mathrm{e}}$ and $\mathrm{q}_{\mathrm{t}}$ are the amounts of solute sorbed per unit adsorbent at equilibrium $(\mathrm{mg} / \mathrm{g})$ and at time $t$, respectively.

Separating variables of (2), integrating and reordered one can obtain the following lineal expression:

$$
\frac{\mathrm{t}}{\mathrm{q}_{\mathrm{t}}}=\frac{1}{\mathrm{k}_{2} \mathrm{q}_{\mathrm{e}}^{2}}+\frac{\mathrm{t}}{\mathrm{q}_{\mathrm{e}}}
$$

The intraparticle diffusion model (Weber-Morris [29] is:

$$
\mathrm{q}_{\mathrm{t}}=\mathrm{k}_{\text {dif }} \mathrm{t}^{0.5}+\mathrm{C}
$$

where $\mathrm{k}_{\mathrm{dif}}$ is the intraparticle diffusion rate constant and $\mathrm{C}$ can be obtained from the slope and intercept of the plot $\mathrm{q}_{\mathrm{t}}$ vs. $\mathrm{t}^{0.5}$.

The correlation coefficient $\left(\mathrm{R}^{2}\right)$ of pseudo-first-order (1), are nearly $0.86(\mathrm{OP})$ and $0.54(\mathrm{RH})$, and $\mathrm{q}_{\mathrm{e}}$ calculated with (1) are lower than the experimental $\mathrm{q}_{\mathrm{e}}$. Therefore, the pseudo-first-order equation is not a good fit for $\mathrm{Cr}$ (III) adsorption on OP and $\mathrm{RH}$.

The kinetic adsorption data were further fitted by the pseudo-second-order kinetic model, using (3). Table 2 shows the experimental $\mathrm{q}_{\mathrm{e}}, \mathrm{k}_{2}, \mathrm{R}^{2}$ values, and the calculated $\mathrm{q}_{\mathrm{e}}$ values which agree perfectly with the experimental $\mathrm{q}_{\mathrm{e}}$ values. Those results indicate that the ratelimiting step is a chemical sorption involving valance 
Table 2. Kinetic parameters from pseudo-second-order for Cr(III) sorption.

\begin{tabular}{ccccc}
\hline Biomaterial & $\begin{array}{c}\mathrm{k}_{2} \\
(\mathrm{~g} / \mathrm{mg} \text { min })\end{array}$ & $\begin{array}{c}\mathrm{q}_{\mathrm{e}}(\mathrm{exp}) \\
(\mathrm{mg} / \mathrm{g})\end{array}$ & $\begin{array}{c}\mathrm{q}_{\mathrm{e}}(\text { calc }) \\
(\mathrm{mg} / \mathrm{g})\end{array}$ & $\mathrm{R}^{2}$ \\
\hline OP & 0.14 & 0.83 & 0.88 & 0.9975 \\
$\mathrm{RH}$ & 2.26 & 0.40 & 0.42 & 0.9997 \\
\hline
\end{tabular}

force through sharing between adsorbent and adsorbate.

The intraparticle diffusion kinetic model (4) provides information about the nature of the adsorption process [29]. A plot of $\mathrm{q}_{\mathrm{t}} \mathrm{vs} \cdot \mathrm{t}^{0.5}$ for $\mathrm{Cr}(\mathrm{III})$ adsorption on OP and $\mathrm{RH}$ afforded two linear sections. A deviation of the straight line from the origin indicates that the intraparticle diffusion is not the only rate controlling step [30] and boundary layer diffusion controls the adsorption to some. If the regression of $\mathrm{q}_{\mathrm{t}}$ vs. $\mathrm{t}^{0.5}$ is linear and passes through the origin, intraparticle diffusion is the sole rate-controlling step [31]. The first straight portion was attributed to the fast mass transfer of sorbate molecules from the bulk solution to the sorbent surface and the second linear portion to the slower intraparticle diffusion into the biosorbent. Similar results were found for acid dye adsorption on activated palm ash [32].

Additionally, the kinetic model proposed by Boyd et al. [33] was applied to check that sorption proceeds via surface uptake followed by intra-particle diffusion:

$$
\mathrm{F}=1-\left(\frac{6}{\pi^{2}}\right) \mathrm{e}^{-\mathrm{Bt}}
$$

where $\mathrm{F}$ is the fraction of solute adsorbed at different times t:

$$
F=\left(\frac{q_{t}}{q_{e}}\right)
$$

$\mathrm{Bt}$, in (5), is a mathematical function of $\mathrm{F}$ which can be evaluated from each value of $F$ as:

$$
\mathrm{Bt}=-0.4977-\ln \left(1-\frac{\mathrm{q}_{\mathrm{t}}}{\mathrm{q}_{\mathrm{e}}}\right)
$$

Plot of Bt vs. $t$ for both, OP and RH, are shown in Figure 9 which are straight lines with $\mathrm{R}^{2}$ of 0.9970 and 0.9921 , respectively. The results suggest that intraparticle diffusion is not the sole rate controlling step because the plot does not pass through the origin. This is in agreement with the results obtained by using intraparticle diffusion model and, at the same time, indicating that the mechanism of metal adsorption by OP and RH is complex and both, external mass transport as well as intraparticle diffusion contribute to the rate determining step, being the rate limiting step the intraparticle transfer.

Value of rate constant B was calculated from the slope in Figure 9 and used to calculate the effective diffusion coefficient, $D_{i}\left(\mathrm{~cm}^{2} / \mathrm{s}\right)$ employing the relationship:

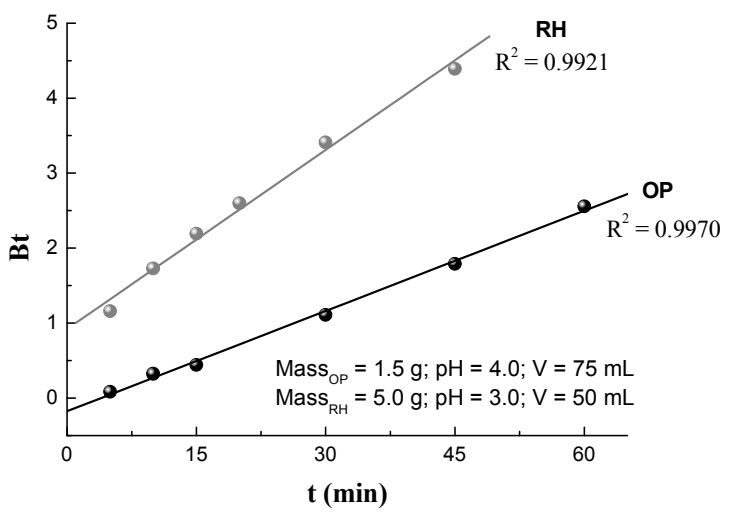

Figure 9. Boyd plot for $\mathrm{Cr}$ (III) sorption. $\mathrm{T}=20^{\circ} \mathrm{C}$; $[\mathrm{Cr}(\mathrm{III})]_{0}=0.385 \mathrm{mM}(\mathrm{OP})$ and $0.77 \mathrm{mM}(\mathrm{RH})$.

$$
\mathrm{B}=\pi^{2} \quad \frac{\mathrm{D}_{\mathrm{i}}}{\mathrm{r}^{2}}
$$

where $r$ represents the radius of the assumed spherical particle. The calculated $D_{i}$ values for OP and RH were $9.5 \times 10^{-8} \mathrm{~cm}^{2} / \mathrm{s}$ and $5.9 \times 10^{-8} \mathrm{~cm}^{2} / \mathrm{s}$, respectively.

\subsection{Adsorption Isotherms}

Freundlich, Langmuir and Dubinin-Radushkevich (D-R) adsorption models were employed for describing the chromium biosorption behavior in the OP- and RH-Cr(III) systems.

Freundlich isotherm

$$
\mathrm{q}_{\mathrm{e}}=\mathrm{K}_{\mathrm{f}} \mathrm{C}_{\mathrm{e}}{ }^{1 / \mathrm{n}}
$$

where $C_{e}$ is equilibrium concentration of chromium in the bulk solution $(\mathrm{mg} / \mathrm{L}), \mathrm{K}_{\mathrm{f}}$ and $1 / \mathrm{n}$ are Freundlich constants. Values of $1 / \mathrm{n}$ and $\mathrm{K}_{\mathrm{f}}$ correspond to the adsorption intensity and maximum adsorption capacity, respectively. This empirical model can be applied to non-ideal adsorption on heterogeneous surfaces as well as multilayer adsorption. Relatively higher fractional values of $1 / \mathrm{n}(0<$ $1 / \mathrm{n}<1)$ indicate a fair validity of classical Freundlich isotherm over the entire concentration of Chromium [34].

Langmuir isotherm

$$
\mathrm{q}_{\mathrm{e}}=\frac{\mathrm{q}_{\mathrm{m}} \mathrm{K}_{\mathrm{L}} \mathrm{C}_{\mathrm{e}}}{1+\mathrm{K}_{\mathrm{L}} \mathrm{C}_{\mathrm{e}}}
$$

where $\mathrm{q}_{\mathrm{m}}$ is the monolayer adsorption capacity $(\mathrm{mg} / \mathrm{g}$ ) and $\mathrm{K}_{\mathrm{L}}$ is the Langmuir constant related to the free energy of adsorption. High values of $\mathrm{K}_{\mathrm{L}}$ are reflected by the step initial slope of a sorption isotherm and indicate a high affinity for the adsorbate.

The non-linear Freundlich and Langmuir isotherms for the uptake of $\mathrm{Cr}$ (III) on the $\mathrm{OP}$ and $\mathrm{RH}$ are presented in Figures 10 and 11. The solid curves represent the model fits in the wide range of concentrations. The corresponding Freundlich and Langmuir parameters together with 


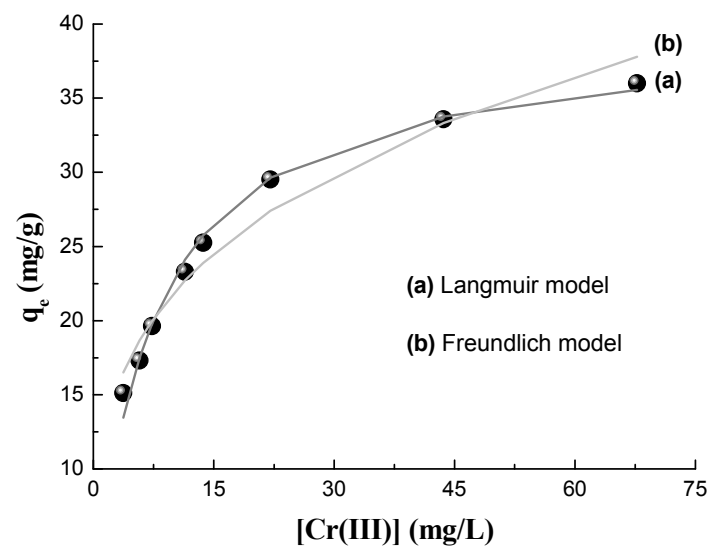

Figure 10. Adsorption isotherm for $\mathrm{Cr}$ (III) removal by $\mathrm{OP}$. Mass $_{\mathrm{OP}}=1.45 \mathrm{~g} ; \mathrm{T}=20^{\circ} \mathrm{C} ; \mathrm{pH}=4.4 ; \mathrm{V}=75 \mathrm{~mL} ;[\mathrm{Cr}(\mathrm{III})]_{0}$ $=76.96-769.60 \mathrm{mg} / \mathrm{L}$; time contact $=120 \mathrm{~min}$.

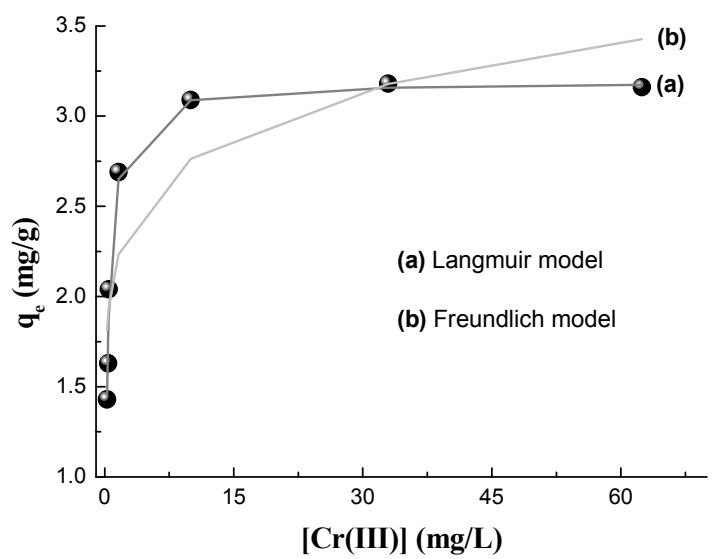

Figure 11. Adsorption isotherm for $\mathrm{Cr}$ (III) removal by $\mathrm{RH}$. Mass $_{\mathrm{RH}}=5.65 \mathrm{~g} ; \mathrm{pH}=3.0 ; \mathrm{T}=20^{\circ} \mathrm{C} ; \mathrm{V}=50 \mathrm{~mL} ;[\mathrm{Cr}(\mathrm{III})]_{0}$ $=23.09-461.76 \mathrm{mg} / \mathrm{L}$; time contact $=120 \mathrm{~min}$.

correlation coefficients are given in Table 3. In the given concentration range, the correlation coefficients showed that the Langmuir model fitted the experimental data better than the Freundlich model.

In previous studies [34,35], authors have suggested that using a dimensionless separation factor is suitable for evaluation of sorption data. For the Langmuir-type sorption process, the isotherm shape can be classified by a term $\mathrm{R}_{\mathrm{L}}$, dimensionless constant separation factor, which is defined as:

$$
\mathrm{R}_{\mathrm{L}}=\frac{1}{1+\mathrm{K}_{\mathrm{L}} \mathrm{C}_{0}}
$$

where $\mathrm{C}_{0}$ is initial metal concentration. The parameter $\mathrm{R}_{\mathrm{L}}$ indicates the shape of the isotherm accordingly: $R_{L}>1$ unfavorable; $\mathrm{R}_{\mathrm{L}}=1$ linear; $0<\mathrm{R}_{\mathrm{L}}<1$ favorable; $\mathrm{R}_{\mathrm{L}}=0$ irreversible. The values of $R_{L}$ were found to be less than 1 and greater than 0 for both biomaterials indicating a favorable adsorption for $\mathrm{Cr}(\mathrm{III})$ by the biomass.
Table 3. Langmuir and Freundlich constants and correlation coefficients for $\mathrm{Cr}$ (III) removal.

\begin{tabular}{ccccccc}
\hline & \multicolumn{3}{c}{ Langmuir constants } & \multicolumn{3}{c}{ Freundlich constants } \\
\hline Biomaterial & $\begin{array}{c}\mathrm{q}_{\mathrm{m}} \\
(\mathrm{mg} / \mathrm{g})\end{array}$ & $\begin{array}{c}\mathrm{K}_{\mathrm{L}} \\
(\mathrm{L} / \mathrm{mg})\end{array}$ & $\mathrm{R}^{2}$ & $\begin{array}{c}\mathrm{K}_{\mathrm{f}} \\
(\mathrm{mg} / \mathrm{g})\end{array}$ & $1 / \mathrm{n}$ & $\mathrm{R}^{2}$ \\
\hline OP & 39.11 & 0.14 & 0.9902 & 11.30 & 0.29 & 0.9687 \\
$\mathrm{RH}$ & 3.20 & 2.98 & 0.9864 & 2.11 & 0.12 & 0.8173 \\
\hline
\end{tabular}

\section{$D-R$ isotherm model [36]}

$$
\ln \mathrm{q}_{\mathrm{e}}=\ln \mathrm{q}_{\mathrm{M}}-\beta \varepsilon^{2}
$$

where $\mathrm{q}_{\mathrm{M}}$ is maximum amount of ion that can be sorbed onto unit weight of sorbent $(\mathrm{mol} / \mathrm{g}), \beta$ is a constant related to sorption energy $(\mathrm{mol} / \mathrm{kJ})$ and $\varepsilon$ is the Polanyi potential:

$$
\varepsilon=\mathrm{R} T \ln \left(1+\frac{1}{\mathrm{C}_{\mathrm{e}}}\right)
$$

where $\mathrm{R}$ is gas constant $\left(8.314 \times 10^{-3} \mathrm{~kJ} / \mathrm{mol} \mathrm{K}\right)$ and $\mathrm{T}$ is absolute temperature expressed in $\mathrm{K}$. Constant $\beta(-3.7 \times$ $\left.10^{-9} \mathrm{~mol}^{2} / \mathrm{J}^{2}\right)$ and $\mathrm{q}_{\mathrm{m}}\left(9.60 \times 10^{-4} \mathrm{~mol} / \mathrm{g}\right)$ values were obtained from slope and intercept of the plot of $\ln \mathrm{q}_{\mathrm{e}} \mathrm{vs}$. $\varepsilon^{2}\left(R^{2}=0.9891\right),(10)$ and Figure 12. The mean sorption energy, $\mathrm{E}$, which is the free energy mean of transference for $1 \mathrm{~mol}$ of solute from infinity (in solution) to the surface of biomaterial, can be calculated from:

$$
\mathrm{E}=\frac{1}{\sqrt{-2 \beta}}
$$

The obtained value of $\mathrm{E}=11.6 \mathrm{~kJ} / \mathrm{mol}$, is in the expected range of $8-16 \mathrm{~kJ} / \mathrm{mol}$ for ion exchange phenomena [36]. The correlation coefficient for RH was lower than OP system (0.9136) using D-R model with an estimate value of $E$ of $16 \mathrm{~kJ} / \mathrm{mol}$.

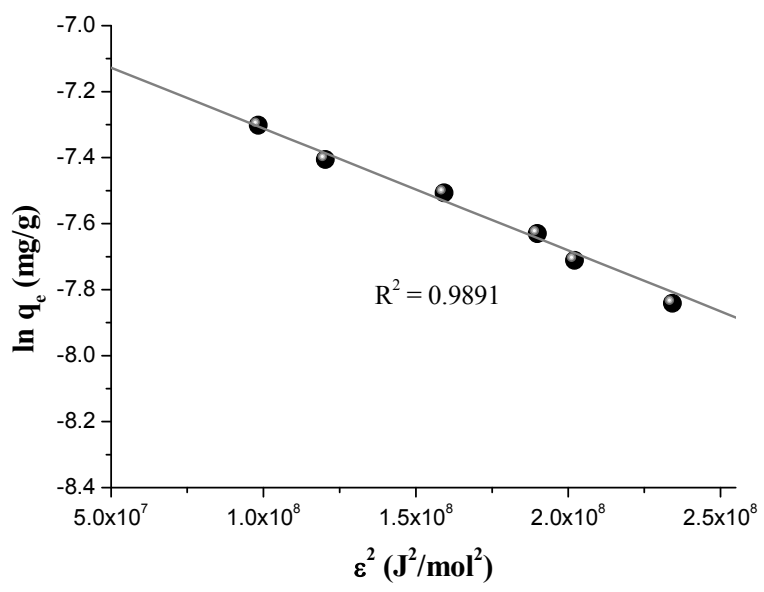

Figure 12. D-R isotherm plot for sorption $\mathrm{Cr}$ (III) onto OP. Mass $_{\mathrm{OP}}=1.45 \mathrm{~g} ; \mathrm{T}=20^{\circ} \mathrm{C} ; \mathrm{pH}=4.4 ; \mathrm{V}=75 \mathrm{~mL} ;[\mathrm{Cr}(\mathrm{III})]_{0}$ $=76.96-769.60 \mathrm{mg} / \mathrm{L}$; time contact $=120 \mathrm{~min}$. 


\section{Conclusions}

$\mathrm{OP}$ and RH agriculture biowaste materials were exam ined as possible low-cost sorbents for $\mathrm{Cr}(\mathrm{III})$ removal from aqueous solutions. Fitting of the intraparticle diffusion model indicated that intraparticle mass transfer resistance is likely the rate limiting phenomenon. The effective diffusion coefficient values for OP and RH were $9.5 \times 10^{-8} \mathrm{~cm}^{2} / \mathrm{s}$ and $5.9 \times 10^{-8} \mathrm{~cm}^{2} / \mathrm{s}$. Sorption dynamics data indicated that the time required to reach sorption equilibrium was approximately $120 \mathrm{~min}$. Langmuir, Freundlich and Dubinin-Radushkevich sorption isotherm models were fitted to the experimentally derived biosorption isotherms. The isotherm data most accurately conformed to the Langmuir equation. The values obtained for $\mathrm{q}_{\mathrm{m}}$ were 39.11 and $3.20 \mathrm{mg} / \mathrm{g}$ for $\mathrm{Cr}$ (III) adsorption by OP and RH, respectively. The mean free energy of metal sorption process calculated from D-R parameter and the Polanyi potential was found to be in the range of $8-16 \mathrm{~kJ} / \mathrm{mol}$ indicating that the main mechanism governing the sorption process is most likely ion exchange. Abiotic $\mathrm{Cr}(\mathrm{VI})$ reduction by the biomass was performed with various contact times, and characteristics of the Cr-laden biomass were determined by spectroscopic studies that demonstrated that the $\mathrm{Cr}(\mathrm{VI})$ bound to the biomass was reduced to $\mathrm{Cr}(\mathrm{III})$. Results indicated that $\mathrm{OP}$ and RH are biomaterials quite effective in removing Chromium from aqueous solutions to drinking water standards.

\section{Acknowledgements}

We thank the National Research Council of Argentina (CONICET) PIP 0075, National University of Rosario (UNR) PIP BIO145 for financial support. J. Ferrón thanks for a Grant PME 82003 for financing the purchase of a Multi Analysis System. L. F. Sala and M. Harada thank the Photon Factory Advisory Committee (PAC) at the High Energy Accelerator Research Organization (KEK) for approval to perform XAFS measurements (Proposal No. 2009G184). P. Blanes thanks the National Academy of Exact, Physic and Natural Sciences for grating a $\mathrm{PhD}$ fellowship.

\section{References}

[1] S. K. Sahu, P. Meshram, B. D. Pandey, V. Kumar and T. R. Mankhand, "Removal of Chromium(III) by Cation Exchange Resin, Indion 790 for Tannery Waste Treatment," Hydrometallurgy, Vol. 99, No. 3-4, November 2009, pp. 170-174.

[2] L. Yang and J. P. Chen, "Biosorption of Hexavalent Chromium onto Raw and Chemically Modified Sargas- sum sp.," Bioresource Technology, Vol. 99, No. 1, January 2008, pp. 297-307.

[3] M. Cieslak-Golonka, "Toxic and Mutagenic Effects of Chromium(VI),. A Review," Polyhedron, Vol. 15, No. 21, August 1996, pp. 3667-3675.

[4] J. C. González, S. I. García, S. Bellú, A. M. Atria, J. M. Salas Peregrín, A. Rockembauer, L. Korecz, S. Signorella and L. F. Sala, "Oligo and Polyuronic Acids Interactions with Hypervalent Chromium," Polyhedron, Vol. 28, No. 13, September 2009, pp. 2719-2729.

[5] S. E. Bellú, J. C. González, S. I. García, S. R. Signorella and L. F. Sala, "Kinetics and Mechanism of Oxidation of Apple Pectin by $\mathrm{Cr}^{\mathrm{VI}}$ in Aqueous Acid Medium," Journal of Physical Organic Chemistry, Vol. 21, No. 12, December 2008, pp. 1059-1067.

[6] D. Mohan and C. U. Pittman, Jr., "Activated Carbons and Low Cost Adsorbents for Remediation of Tri- and Hexavalent Chromium from Water," Journal of Hazardous Materials, Vol. 137, No. 2, September 2006, pp. $762-$ 811.

[7] U. K. Garg, M. P. Kaur, V. K. Garg and D. Sud, "Removal of Hexavalent Chromium from Aqueous Solution by Agricultural Waste Biomass," Journal of Hazardous Materials, Vol. 140, No. 1-2, February 2007, pp. 60-68.

[8] S. Bellú, S. García, J. C. González, A. M. Atria, L. F. Sala and S. Signorella, "Removal of Chromium(VI) and Chromium(III) form Aqueous Solution by Grainless Stalk of Corn," Separation Science and Technology, Vol. 43, No. 11-12, August 2008, pp. 3200-3220.

[9] M. Krumpolc and J. Rocek, "Sodium bis[2-ethyl-2-hydroxybutyrato(2-)]-oxochromate(V)," Inorganic Syntheses, Vol. 20, 1980, pp. 63-65.

[10] L. Clesceri, A. Greenberg and A. Eaton, "Standard Methods for the Examination of Water and Wastewater," 20th Edition, American Public Health Association, American Water Work Association, and Water Environment Federation, Washington, D.C., 1998, p. 366.

[11] F. Burriel Martí, F. Lucena Conde, S. Arribas Jimeno and J. Hernández Méndez, "Qualitative Analytical Chemistry (Spanish)," 14th Edition, Paraninfo, Madrid, 1992.

[12] M. Nomura and A. Koyama, "Performance of a Beamline with a Pair of Bent Conical Mirrors," Nuclear Instruments and Methods in Physics Research Section A, Vol. 467-468, July 2001, pp. 733-736.

[13] D. C. Koningsberger and R. Prins, "X-Ray Absorption: Principles, Applications, Techniques of EXAFS, SEXAFS, and XANES," John Wiley \& Sons, New York, 1988.

[14] K. K. Kannan and M. A. Viswamitra, "Unit Cell, Space Group and Refractive Indices of $\mathrm{Al}\left(\mathrm{NO}_{3}\right)_{3} \cdot 9 \mathrm{H}_{2} \mathrm{O}$ and $\mathrm{Cr}\left(\mathrm{NO}_{3}\right)_{3} \cdot 9 \mathrm{H}_{2} \mathrm{O}$," Acta Crystallographica, Vol. 19, July 1965, pp. 151-152.

[15] H. Sakane, A. Munoz-Páez, S. Díaz-Moreno, J. M. Martínez, R. Pappalardo and E. Sánchez Marcos, "Second Hydration Shell Single Scattering versus First Hydration Shell Multiple Scattering in $\mathrm{M}\left(\mathrm{H}_{2} \mathrm{O}\right)_{6}{ }^{3+}$ EXAFS Spectra," Journal of the American Chemical Society, Vol. 120, No. 40, October 1998, pp. 10397-10401. 
[16] D. Park, Y.-S. Yun and J. M. Park, "XAS and XPS Studies on Chromium-Binding Groups of Biomaterial during $\mathrm{Cr}(\mathrm{VI})$ Biosorption," Journal of Colloid and Interface Science, Vol. 317, No. 1, January 2008, pp. 54-61.

[17] G. Barr-David, M. Charara, R. Codd, R. P. Farrell, J. A. Irwin, P. A. Lay, R. Bramley, S. Brumby, J.-Y. Ji and G. R. Hanson, "EPR Characterization of the $\mathrm{Cr}^{\mathrm{V}}$ Intermediates in the $\mathrm{Cr}^{\mathrm{VI} / \mathrm{V}}$ Oxidations of Organic Substrates and of Relevance to Cr-Induced Cancers," Journal of the Chemical Society, Faraday Transactions, Vol. 91, No. 8, April 1995, pp. 1207-1216.

[18] E. Groppo, C. Prestipino, F. Cesano, F. Bonino, S. Bordiga, C. Lamberti, P. C. Thüne, J. W. Niemantsverdriet and A. Zecchina, "In situ, Cr $K$-Edge XAS Study on the Phillips Catalyst: Activation and Ethylene Polymerization," Journal of Catalysis, Vol. 230, No. 1, February 2005, pp. 98-108.

[19] B. A. Manning, J. R. Kiser, H. Kwon and S. R. Kanel, "Spectroscopic Investigation of $\mathrm{Cr}(\mathrm{III})$ - and $\mathrm{Cr}(\mathrm{VI})-$ Treated Nanoscale Zerovalent Iron," Environmental Science \& Technology, Vol. 41, No. 2, January 2007, pp. 586-592.

[20] A. Levina, R. Codd, G. J. Foran, T. W. Hambley, T. Maschmeyer, A. F. Masters and P. A. Lay, "X-Ray Absorption Spectroscopic Studies of Chromium(V/IV/III)2-Ethyl-2-Hydroxybutanoato(2-/1-) Complexes," Inorganic Chemistry, Vol. 43, No. 3, February 2004, pp. 10461055.

[21] D. Lazar, B. Ribár, V. Divjakovic and Cs. Mészáros, "Structure of Hexaaquachromium(III) Nitrate Trihydrate," Acta Crystallographica Section C, Vol. 47, No. 5, May 1991, pp. 1060-1062.

[22] J. L. Gardea-Torresdey, K. J. Tiemann, V. Armendariz, L. Bess-Oberto, R. R. Chianelli, J. Rios, J. G. Parsons and G. Gamez, "Characterization of Cr(VI) Binding and Reduction to $\mathrm{Cr}(\mathrm{III})$ by the Agricultural Byproducts of Avena Monida (Oat) Biomass," Journal of Hazardous Materials, Vol. 80, No. 1, December 2000, pp. 175-188.

[23] H. Roussel, V. Briois, E. Elkaim, A. de Roy, J.-P. Besse and J.-P. Jolivet, "Study of the Formation of the Layered Double Hydroxide [ $\mathrm{Zn}-\mathrm{Cr}-\mathrm{Cl}]$," Chemistry of Materials, Vol. 13, No. 2, February 2001, pp. 329-337.

[24] P. X. Sheng, Y.-P. Ting, J. P. Chen and L. Hong, "Sorption of Lead, Copper, Cadmium, Zinc, and Nickel by Marine Algal Biomass: Characterization of Biosorptive Capacity and Investigation of Mechanisms," Journal of Colloid and Interface Science, Vol. 275, No. 1, July 2004, pp. 131-141.

[25] C. Liu and P. M. Huang, "Kinetics of Phosphate Adsorp- tion on Iron Oxides Formed under Influence of Citrate," Canadian Journal of Soil Science, Vol. 80, No. 3, August 2000, pp. 445-454.

[26] F. Qin, B. Wen, X.-Q. Shan, Y.-N. Xie, T. Liu, S.-Z. Zhang and S. U. Khan, "Mechanism of Competitive Adsorption of $\mathrm{Pb}, \mathrm{Cu}$ and $\mathrm{Cd}$ on Peat," Environmental Pollution, Vol. 144, No. 2, November 2006, pp. 669-680.

[27] S. Lagergren, "About the Theory of So-Called Adsorption of Soluble Substances, Zur Theorie der Sogenannten Adsorption Gelöster Stoffe," Kungliga Svenska Vetenskapsakademiens, Handlingar, Vol. 24, No. 4, 1898, pp. 1-39.

[28] Y. S. Ho, D. A. J. Wase and C. F. Forster, "Kinetic Studies of Competitive Heavy Metal Adsorption by Sphagnum Moss Peat," Environmental Technology, Vol. 17, No. 1, January 1996, pp. 71-77.

[29] W. J. Weber Jr. and J. C. Morris, "Kinetics of Adsorption on Carbon from Solution," Journal of the Sanitary Engineering Division ASCE, Vol. 89, No. (SA2), 1963, pp. 31-59.

[30] I. D. Mall, V. C. Srivastava and N. K. Agarwal, "Removal of Orange-G and Methyl Violet Dyes by Adsorption onto Bagasse Fly Ash-Kinetic Study and Equilibrium Isotherm Analyses," Dyes and Pigments, Vol. 69, No. 3, June 2006, pp. 210-223.

[31] W. H. Cheung, Y. S. Szeto and G. McKay, "Intraparticle Diffusion Processes during Acid Dye Adsorption onto Chitosan," Bioresource Technology, Vol. 98, No. 15, November 2007, pp. 2897-2904.

[32] B. H. Hameed, A. A. Ahmad and N. Aziz, "Isotherms, Kinetics and Thermodynamics of Acid Dye Adsorption on Activated Palm Ash," Chemical Engineering Journal, Vol. 133, No. 2, September 2007, pp. 195-203.

[33] G. E. Boyd, A. W. Adamson and L. S. Myers Jr., "The Exchange Adsorption of Ions from Aqueous Solutions by Organic Zeolites. II. Kinetics," Journal of the American Chemical Society, Vol. 69, No. 11, 1947, pp. 2836-2848.

[34] L. Khesami and R. Capart, "Removal of Chromium(VI) from Aqueous Solutions by Activated Carbons: Kinetic and Equilibrium Studies," Journal of Hazardous Materials, Vol. 123, No. 1-3, August 2005, pp. 223-231.

[35] Y. S. Ho and C. C. Wang, "Pseudo-Isotherms for the Sorption of Cadmium Ion onto Tree Fern," Process Biochemistry, Vol. 39, No. 6, February 2004, pp. 761-765.

[36] M. M. Dubinin, E. D. Zaverina and L. V. Radushkevich, "Sorption and Structure of Active Carbons. Adsorption of Organic Vapors," Zhurnal Fizicheskoi Khimii, Vol. 21, 1947, pp. 1351-1362. 